\title{
Advertisement-financed credit ratings
}

\author{
Heidrun Hoppe-Wewetzer ${ }^{1} \cdot$ Christian Siemering $^{1}$
}

Accepted: 24 August 2021 / Published online: 8 October 2021

(C) The Author(s) 2021

\begin{abstract}
This paper investigates the incentives of a credit rating agency (CRA) to generate accurate ratings under an advertisement-based business model. To this end, we study a two-period endogenous reputation model in which a CRA can increase the precision of its ratings by exerting effort. The CRA receives a revenue not from rating fees, as is standard in the literature, but through online advertising. We show that the advertisement-based business model provides sufficient incentives for the CRA to improve the precision of signals at intermediate levels of reputation. Furthermore, we identify conditions under which truthful reporting is incentive compatible.
\end{abstract}

Keywords Credit rating agencies · Rating precision · Information acquisition · Advertisement · Reputation

JEL Classification D82 · G24 · L15

\section{Introduction}

Credit rating agencies (CRAs) act as intermediaries on financial markets between issuers of financial products and investors. They assess the creditworthiness of an issuer and publish the results of these assessments usually in the form of ratings to investors. In the past two decades, CRAs have widely been accused of publishing inaccurate ratings. In fact, the three major CRAs - Standard and Poor's Financial Services (S\&P), Moody's Investors Service and Fitch Ratings - have published ratings considered to be investment grade for the American energy company Enron until shortly before Enron filed for bankruptcy in 2001. Also, CRAs have been criticized

Christian Siemering

siemering@mik.uni-hannover.de

Heidrun Hoppe-Wewetzer

hoppe@mik.uni-hannover.de

1 Faculty of Economics and Management, Leibniz University, Hannover, Germany 
for systematically failing to assess the high risk of structured assets like mortgagebacked securities and collateralized debt obligations issued during the U.S. housing boom, and thereby contributing to the financial crisis of 2007-2008. ${ }^{1}$

Hence, a question that has emerged in the recent years is to what extent is the CRA business model responsible for inaccurate ratings. Until the early 1970s, most CRAs relied on the investor-pays model, under which fees for access to ratings are collected from investors. Today, most CRAs, including the three major ones, operate under the issuer-pays model where the revenue for ratings comes in the form of fees paid by the issuers of the securities. Kashyap and Kovrijnykh (2016) analyze and compare these two business models in a setting in which a CRA acquires information about the quality of a financial product under moral hazard. They find that the investorpays model generates more precise ratings than the issuer-pays model, but still not as precise as what a social planner could attain.

The present paper contributes to this line of research by investigating the incentives of a CRA to generate accurate ratings under a different mechanism of CRA financing, namely, the use of an online platform to publish ratings and earn advertising revenue by attracting investors to this platform. To our knowledge the idea of advertisement-financed credit rating, first raised in White (2013), has not been formally analyzed - a surprising fact, given that online marketplaces have proliferated rapidly (Luca 2016; Spulber 2019) and intermediaries that were originally based on a subscriber-pays business model have switched to advertising models in many industries, such as for example TV-stations and newspapers (cf. Evans (2008)). ${ }^{2}$ The main objective of our paper is to investigate whether an advertisement-based business model may provide sufficient incentives for a CRA to generate accurate ratings when increasing the precision of its ratings is costly.

To this end, we study a two-period model in which a CRA receives a noisy signal about the default risk of a financial product in each period. The CRA can exert effort in order to increase the precision of its ratings. This effort choice is unobservable by firms and investors, which creates a moral hazard problem. In the spirit of Kreps and Wilson (1982) and Milgrom and Roberts (1982), we assume that the CRA can be one of two possible types: committed to use the most accurate information technology or opportunistic, i.e., maximizing its continuation payoff. Types are drawn by nature and remain private information. Investors form subjective beliefs that the CRA is committed, measuring the CRA's reputation. If this reputation is high enough such that the CRA's ratings matter for the investment in risky projects, investors get attracted to the CRA's website and advertisement revenue is generated.

It is intuitive, and shown to be optimal, that the CRA will shirk, i.e., not improve the precision of the signals, if its reputation is either below a certain threshold level or above another threshold level. In the former case, future advertisement revenue is shown to be zero, irrespective of the CRA's information technology. In the latter case, future advertisement revenue is positive, but remains constant even when highly-rated projects have failed.

\footnotetext{
${ }^{1}$ See Berenson (2001), White (2016), and Chu and Rysman (2019).

${ }^{2}$ Whereas the newspaper industry typically uses a mix between advertisement and subscription fees, TVstations often use a pure advertisement model.
} 
However, for a range of intermediate reputation levels, increasing the precision of signals is no longer a zero probability event in equilibrium. The key insight of our analysis is that under the advertisement-financed model improving the precision of signals gives rise to two reputation effects: First, more precise signals reduce the probability that a bad project is erroneously rated good (the bad-project-identification effect). This helps the CRA to maintain a reputation level that is high enough so as to attract investors to its website. In fact, exerting effort to increase the precision of signals turns out to be the only equilibrium outcome in this case. Second, more precise signals also reduce the probability that a good project is erroneously rated low (the good-project-identification effect). We show that this effect can help the CRA to build a reputation whenever low ratings would deter investors from visiting the website in the future.

Furthermore, allowing the CRA to misreport the signal that it received about the quality of the financial product, we identify the conditions for truthful reporting in every equilibrium involving reputation maintenance or reputation building. We find that increasing the precision of signals and truth-telling can only be incentivized if the advertisement revenues are state-contingent and sufficiently rewarding when highlyrated projects succeed. The results also have implications for regulatory intervention, such as introducing special liability rules for CRAs (see, e.g., Pacces and Romano 2015), in environments where truthful reporting of ratings cannot be incentivized.

Results by Kashyap and Kovrijnykh (2016) imply that the optimal compensation structure for the CRA must be contingent on the ratings and the project's performance. They discuss, but in contrast to the present paper, do not formally analyze its implementation in a dynamic setting involving reputation concerns. ${ }^{3}$ Our analysis reveals that the incentive-compatible compensation structure identified by Kashyap and Kovrijnykh (2016) can in fact be implemented by an advertisementfinanced business model with state-contingent revenues. Moreover, since revenues are obtained from a third party, namely advertisers, this business model does not suffer from the potential problem of 'rating shopping' associated with the issuer-pays model (see, e.g., Skreta and Veldkamp (2009)) or the problem of the investor-pays model that too many investors could 'free ride' by obtaining photocopies (see, e.g., White (2010)). ${ }^{4}$

Reputation in our model differs from the one in the well-known paper by Mathis et al. (2009). First, we consider the CRA's reputation for being perfectly informed, assuming that the informativeness of the signals depend on the CRA's effort choice, while Mathis et al. (2009) analyze reputation for truthful reporting under the assumption of perfectly informative signals. Second, we study reputational incentives under an advertisement-financed business model, whereas Mathis et al. (2009) focus on the

\footnotetext{
${ }^{3}$ Chakraborty et al. (2019) also take a mechanism approach and characterize incentive compatible compensation schemes by a trust to induce a CRA to exert effort to increase the precision of signals and report the signals truthfully. In contrast to the business model considered in our paper, their mechanism depends upon the presence of a centralized authority specifying outcome-contingent payments and enforcing the rules.

${ }^{4}$ See Sangiori and Spatt (2017) for a discussion of the different frictions associated with paying for information in the context of credit ratings.
} 
issuer-pays model. Interestingly, Mathis et al. (2009) advocate to eliminate any direct commercial links between CRAs and issuers - a structure that is obtained under the advertisement-financed credit rating considered in our paper. For a discussion of the policy proposals based on the findings of Mathis et al. (2009), see Jaffee (2009). Other papers on reputation building by CRAs under the issuer-pays model include, for example, Fulghieri et al. (2014) and Frenkel (2015). Fulghieri et al. (2014) consider a two-period reputation model with solicited and unsolicited ratings. They show that unsolicited ratings are lower because all favorable ratings are solicited. By contrast, in our advertisement-financed model, all ratings are unsolicited. Frenkel (2015) shows that a CRA may also have an incentive to develop a reputation for lax rating standards among issuers. These reputational concerns can exacerbate the problem of rating inflation - an effect which is not present under advertisement financing. Moreover, information acquisition is costless in his model. Thus, there is no reputational incentive for producing more informative signals, which is the main focus of our paper.

At a broader level, our paper is related to the literature on certification, e.g. Strausz (2005) and Bouvard and Levy (2018). These papers investigate markets on which the quality of the traded good is unobservable to buyers. Buyers and sellers may both pay for certification because they benefit from signaling their quality or respectively learning the quality of the offered good. In fact, a CRA is an example for a certifier that can be paid either by sellers (issuers), buyers (investors), or a third party such as advertisers.

The remainder of this paper is structured as follows. The next section describes the model of credit rating under the advertisement-based business model. The equilibrium analysis is provided in Section 3. Section 4 introduces and analyzes an extension in which misreporting is possible. Finally, Section 5 provides a summary of our findings and concludes. All proofs are placed in the Appendix.

\section{The model}

We consider a simple financial market model with two periods $(t=1,2)$ and no discounting, based on those of Mathis et al. (2009) and Kashyap and Kovrijnykh (2016). At each period, a wealthless firm seeks financing to invest in a risky project of a size normalized to 1 that generates a return $X>1$ in the event of success and 0 in the event of failure. The probability of success depends on the project's type $\tau_{t}$, which can be good or $b a d, \tau_{t} \in\{g, b\}$. A good project is successful with probability $\alpha$ and fails with probability $1-\alpha$, while a bad project always fails. ${ }^{5}$ The project's type is unknown a priori: All agents believe ex ante that the project is good with probability $\lambda$, and bad with probability $1-\lambda$, where $0<\lambda \leq 1 / 2$. This assumption

\footnotetext{
${ }^{5}$ In the model of Mathis et al. (2009), the probability of success for the bad project is assumed to be less than the probability of success for the good project, but positive.
} 
that good projects are scarce creates a role for the CRA to acquire information in order to find out whether a project is good or bad and facilitates the analysis. ${ }^{6}$

At each period, there is a number $(n \geq 2)$ of identical investors. In particular, all investors have the same prior beliefs and they face the same outside option. Investors are risk neutral and competitive. They can invest either in the firm's project or in an outside option with a certain return, normalized to 1 . Each firm promises to pay a return $R$, where $0 \leq R \leq X$, to investors if the project is financed and successful. A project that is not financed cannot be carried out and is not available in future periods. Assume that

$$
\lambda \alpha X<1<\alpha X
$$

The first part of (A1) implies that investors would not invest without any further information about the project's type. The second part implies that investment would take place when there is no uncertainty.

A credit rating agency (CRA) receives information about the project's type. Whereas firms and investors are short-lived players (for one period), the CRA is a long-lived player (for two periods). The CRA obtains a private signal $\sigma_{t} \in\{L, H\}$, unfavorable $(L)$ or favorable $(H)$, about the firm's project type in period $t$. The signal may be noisy, which is in contrast to the model of Mathis et al. (2009) in which signals are assumed to be perfectly informative. Instead, following Kashyap and Kovrijnykh (2016), we assume that the CRA can exert effort in order to increase the precision of the signals. In particular, all investors have the same prior beliefs and they face the same outside option. Let $s_{t}$ be the CRA's effort exerted to increase the informativeness of the signal about the project's type in period $t$, and let the probability that the signal is favorable, given that the project is good, be

$$
\operatorname{Pr}\left(\sigma_{t}=H \mid \tau_{t}=g\right)=\operatorname{Pr}\left(\sigma_{t}=L \mid \tau_{t}=b\right)=\frac{1}{2}+s_{t}, \quad 0 \leq s_{t} \leq \frac{1}{2}
$$

The effort $s_{t}$ in the precision of the signal entails a cost of $c\left(s_{t}\right)$, with $c(0)=c^{\prime}(0)=$ $0, c^{\prime}\left(s_{t}\right)>0$ for $s_{t}>0$ and $c^{\prime \prime}\left(s_{t}\right) \geq 0$. We assume that the CRA's effort is unobserved by firms and investors and unverifiable. Thus, the CRA cannot be directly rewarded for exerting effort to acquire more precise signals. Typically, a CRA's incentives come from possible reputation cost it incurs when it provides inaccurate information. We address the issue in the following reputation game. In the spirit of Kreps and Wilson (1982) and Milgrom and Roberts (1982), let the CRA be one of two types, $\theta \in\{C, O\}$, i.e., committed to receive a perfectly informative signal $(C)$ or opportunistic $(O)$ in which case it may obtain an imperfect of even completely uninformative signal. Note that one could alternatively assume that the "committed type' faces zero costs of increasing the signal precision. The CRA's types are private information and investors believe that, at the beginning of period 1, these types are randomly drawn with probability

$$
\operatorname{Pr}(\theta=C)=\varphi_{1} \quad \text { and } \quad \operatorname{Pr}(\theta=O)=1-\varphi_{1}, \quad 0 \leq \varphi_{1} \leq 1
$$

\footnotetext{
${ }^{6}$ In a more simplified version, one could restrict attention to the case of $\lambda=1 / 2$, such as, for instance, in the model of Bolton et al. (2012). Extending the analysis to the case of $\lambda>1 / 2$ is rather straightforward and available from the authors on request. Briefly, the opportunistic CRA has an incentive to deflate ratings for a broader variety of reputation levels.
} 
We assume that the observed signal is truthfully reported to investors in the form of a rating, i.e., either good $\left(r_{t}=H\right)$ or bad $\left(r_{t}=L\right) .{ }^{7}$ That is, the CRA disseminates only correct information. The assumption is made to capture, in a simple way, the fact that, otherwise, the CRA may face potential legal damage. By contrast, Mathis et al. (2009) treat the CRA's information production technology as exogenous and focus on the CRA's incentive of misreporting, i.e., giving a good rating when the CRA believes that the project is bad. We will extend our basic framework below to allow for both, shirking and misreporting, as in Kashyap and Kovrijnykh (2016).

A novel element in this line of research is introduced by assuming that the CRA earns a revenue through an advertising-financed business model. For recent surveys of the literature on advertising-financed business models in other industries, see, e.g. Anderson (2012), Anderson and Jullien (2015). Here, we consider a CRA who, in each period, publishes its rating on a website that investors can visit without any subscription fees. If the site attracts sufficient attention from investors, advertisers are willing to place ads on this site which generates a positive advertisement revenue $\pi>0$ for the CRA in that period. Investors are willing to visit the website whenever they believe that the CRA's ratings will influence their investment decision. We show that this occurs if and only if the CRA's reputation of publishing an accurate rating is high enough. Otherwise, the advertisement revenue will be 0 . This happens when the observation of good and bad ratings would both lead to the same investment decision. Note that, despite its simplicity, the revenue structure incorporates one of the most important characteristics of the advertisement industry, namely, that expected revenue is increasing in the "attention" that a website attracts (cf. Ahmed and Kwon (2012)).

For period 1, the order of play is represented by the game trees depicted in Fig. 1.

At the beginning of period 1, the committed CRA exerts effort $s_{1}=1 / 2$, whereas the opportunistic CRA type chooses an effort level of $0 \leq s_{1} \leq 1 / 2$. Each CRA type then observes a signal and reports it truthfully on its website in the form of a rating, $r_{1} \in\{L, H\}$. The firm sets $R_{1}, 0 \leq R_{1} \leq X$, i.e., the return to investors if the project is financed and successful. Investors then choose whether to visit the website or not. Their prior belief at the beginning of period 1 that the CRA is committed to obtain perfectly informative signals is $\varphi_{1}$ (see left tree in Fig. 1). This is interpreted as the CRA's reputation for receiving precise signals at the beginning of period 1 . When investors visit the website, they observe the reported rating and update their prior beliefs according to Bayes' rule. Based on these interim beliefs, they decide whether to invest in the project or not (see right tree in Fig. 1). If the project is financed, investors' interim beliefs are updated according to Bayes' rule after the outcome of the firm's investment project is observed - resulting in final beliefs. If the project

\footnotetext{
${ }^{7}$ It is obviously a simplification to allow only for two different rating scores. In the real world, finer partitions of ratings can be observed. Standard \& Poor's, for instance, uses 24 rating grades, which span from AAA to D. Hereby, the best ten rating grades, from AAA to BBB-, are considered to be investment grade. The remaining 14 grades, from $\mathrm{BB}$ - to $\mathrm{D}$, are considered to be speculative grade.
} 


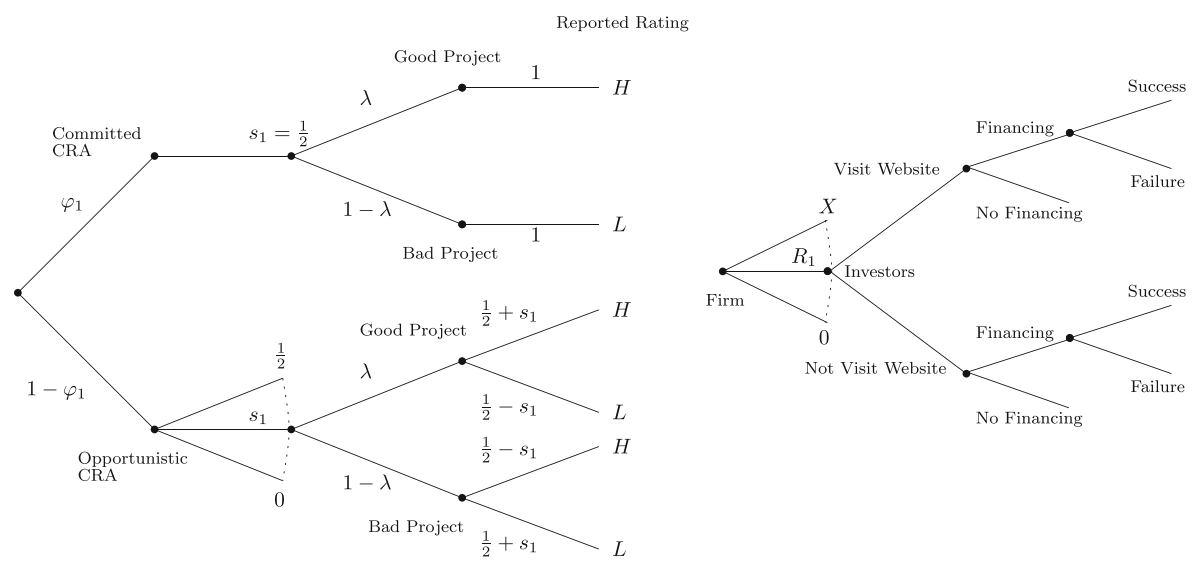

Fig. 1 First period play

is not financed, investors' interim beliefs are not updated further. Investors' final beliefs at the end of period 1 determine the prior beliefs of investors at the beginning of period 2, measuring the CRA's reputation in that period. That is, like e.g. in Mathis et al. (2009), we make the standard underlying assumption that word-ofmouth emerges and evolves over generations within a network of investors. ${ }^{8}$ This information structure ensures that all relevant information for the second-period decisions is summarized in the CRA's reputation parameter $\varphi_{2}$. Based on $\varphi_{2}$, all stages of period 1, except nature's initial choice of the CRA's type, are then repeated in period 2.

Let $\tilde{s}_{t}$ denote the investors' belief about the opportunistic CRA's effort choice in each period $t$. To ease the exposition, we make use of the following definitions:

$$
\begin{aligned}
\varphi_{t}^{H} & \equiv \operatorname{Pr}\left(\theta=C \mid r_{t}=H\right)=\frac{\varphi_{t} \lambda}{\varphi_{t} \lambda+\left(1-\varphi_{t}\right)\left[\lambda\left(\frac{1}{2}+\tilde{s}_{t}\right)+(1-\lambda)\left(\frac{1}{2}-\tilde{s}_{t}\right)\right]} \\
\varphi_{t}^{L} & \equiv \operatorname{Pr}\left(\theta=C \mid r_{t}=L\right)=\frac{\varphi_{t}(1-\lambda)}{\varphi_{t}(1-\lambda)+\left(1-\varphi_{t}\right)\left[\lambda\left(\frac{1}{2}-\tilde{s}_{t}\right)+(1-\lambda)\left(\frac{1}{2}+\tilde{s}_{t}\right)\right]}
\end{aligned}
$$

That is, $\varphi_{t}^{H}$ and $\varphi_{t}^{L}$ are the investors' interim beliefs in period $t$ that the CRA is committed to obtain perfectly informative signal, after it reports an $H$-rating and

\footnotetext{
${ }^{8}$ A formal model of information transmission within networks is provided, for instance, by Lippert and Spagnolo (2011). It seems interesting to investigate whether the use of online platforms may affect the nature of word-of-mouth among investors and thus the opportunities for reputation building. This issue has been addressed before in the marketing/advertising literature as well as the psychology literature. See, for instance, Lu et al. (2013), Chu and Kim (2018), and Huete-Alcocer (2017). We leave this issue for future research.
} 
$L$-rating, respectively. The investors' updated beliefs in that period that the project is good are then, respectively,

$$
\begin{aligned}
& \lambda_{t}^{H} \equiv \operatorname{Pr}\left(\tau_{t}=g \mid r_{t}=H\right)=\varphi_{t}^{H}+\frac{\left(1-\varphi_{t}^{H}\right) \lambda\left(\frac{1}{2}+\tilde{s}_{t}\right)}{\lambda\left(\frac{1}{2}+\tilde{s}_{t}\right)+(1-\lambda)\left(\frac{1}{2}-\tilde{s}_{t}\right)} \\
& \lambda_{t}^{L} \equiv \operatorname{Pr}\left(\tau_{t}=g \mid r_{t}=L\right)=\frac{\left(1-\varphi_{t}^{L}\right) \lambda\left(\frac{1}{2}-\tilde{s}_{t}\right)}{\lambda\left(\frac{1}{2}-\tilde{s}_{t}\right)+(1-\lambda)\left(\frac{1}{2}+\tilde{s}_{t}\right)}
\end{aligned}
$$

Furthermore, we define the investors' final beliefs that the CRA is committed to obtain accurate signals at the end of period 1 , given an $H$-rating and project success $(S)$ or failure $(F)$, respectively,

$$
\begin{aligned}
\varphi_{1}^{H S} & \equiv \operatorname{Pr}\left(\theta=C \mid r_{1}=H, S\right)=\frac{\varphi_{1}}{\varphi_{1}+\left(1-\varphi_{1}\right)\left(\frac{1}{2}+\tilde{s}_{1}\right)} \\
\varphi_{1}^{H F} & \equiv \operatorname{Pr}\left(\theta=C \mid r_{1}=H, F\right) \\
& =\frac{(1-\alpha) \lambda \varphi_{1}}{(1-\alpha) \lambda \varphi_{1}+\left(1-\varphi_{1}\right)\left((1-\alpha) \lambda\left(\frac{1}{2}+\tilde{s}_{1}\right)+(1-\lambda)\left(\frac{1}{2}-\tilde{s}_{1}\right)\right)}
\end{aligned}
$$

It is straightforward to verify that $0 \leq \lambda \leq 1 / 2$ and (A1) imply that

$$
\varphi_{1}^{H F} \leq \varphi_{1}^{H} \leq \varphi_{1} \leq \varphi_{1}^{L} \leq \varphi_{1}^{H S}
$$

with equality signs at $\tilde{s}_{1}=1 / 2$. Notably, the CRA's final reputation of being perfectly informed rises when the CRA reports an $L$-rating, and is highest when an $H$-rated project turns out to be successful and lowest when it fails. The event that an $H$-rated project fails may occur in three different cases: First, when the CRA is committed to obtain an accurate signal and a good project fails; second, when the CRA is opportunistic and a good project fails; and third, when the CRA is opportunistic and a bad project fails that has been rated high erroneously. Although financing in the two former cases is ex ante efficient, the project fails ex post due to bad luck. This is in contrast to the third case where the investment decision is also ex ante inefficient.

The equilibrium concept in our model is perfect Bayesian equilibrium.

\section{Equilibrium analysis}

We first consider the decision problems of the firms and investors. Recall that both are short-lived players. Thus, they only care about actions of the actual period. Accordingly, it is not necessary to differentiate between first and second period agents. For given beliefs about the CRA's type $\varphi_{t}$ and effort choice $\tilde{s}_{t}$ in period $\mathrm{t}$, investors will find it optimal to finance the project after observing an $H$-rating whenever

$$
\alpha \lambda_{t}^{H}\left(\tilde{s}_{t}\right) R_{t} \geq 1
$$


is satisfied. Proceeding backwards, the firm's optimal return choice is given by $R_{t}=$ $\hat{R}_{t}$ such that $\alpha \lambda_{t}^{H}\left(\tilde{s}_{t}\right) \hat{R}_{t}=1$, for $\hat{R}_{t} \leq X$, since its expected payoff is strictly decreasing in $R_{t}$. For $\hat{R}_{t}>X$, the firm cannot induce any investment, and we assume, without loss of generality, that $R_{t}=X$ in such a case. Furthermore, note that the firm cannot induce any investment when the investor observes an $L$-rating or when investors will not visit the website.

We now turn to the opportunistic CRA's effort choice. Define $\hat{\varphi}_{t}\left(\tilde{s}_{t}\right)$ by

$$
\hat{\varphi}_{t}\left(\tilde{s}_{t}\right) \equiv \min \left\{\varphi_{t}\left(\tilde{s}_{t}\right): \alpha \lambda_{t}^{H}\left(\tilde{s}_{t}\right) R_{t} \geq 1\right\}
$$

where $\lambda_{t}^{H}\left(\tilde{s}_{t}\right)$ is defined by Eq. 5 and $R_{t} \leq X$. That is, $\hat{\varphi}_{t}\left(\tilde{s}_{t}\right)$ the lowest CRA's reputation at the beginning of period $t$ such that (10) still holds.

In period 2, the CRA's problem is given by

$$
\max _{\left\{s_{2}\right\}}\left[\mathbb{1}_{\left\{\varphi_{2} \geq \hat{\varphi}_{2}\left(\tilde{s}_{2}\right)\right\}} \pi-c\left(s_{2}\right)\right]
$$

where $\varphi_{2} \in\left\{\varphi_{1}^{H F}, \varphi_{1}, \varphi_{1}^{L}, \varphi_{1}^{H S}\right\}$ depending on the first-period outcome, ${ }^{9}$ and $\mathbb{1}_{\left\{\varphi_{2} \geq \hat{\varphi}_{2}\left(\tilde{s}_{2}\right)\right\}}$ is an indicator function that yields 1 if $\varphi_{2} \geq \hat{\varphi}_{2}\left(\tilde{s}_{2}\right)$ and 0 otherwise. It is straightforward to show that the maximum of (12) is attained at $s_{2}=0$. To understand this, note that whether advertisement revenue is generated or not is determined solely by the market conditions, as captured by $\alpha, \lambda$, and $X$, and by the investors' beliefs $\varphi_{2}$ and $\tilde{s}_{2}$, which cannot be influenced by the CRA in that period, whereas the marginal cost are $c^{\prime}\left(s_{2}\right)>0$ for all $s_{2}>0$. The second-period equilibrium play is summarized in the next proposition. The proof is placed in the Appendix.

Proposition 1 There is a unique equilibrium of the second-period play. In this equilibrium, the opportunistic CRA chooses $s_{2}=0$. Furthermore, investment takes place whenever the rating is good and $\varphi_{2} \geq \hat{\varphi}_{2}(0)$, where $\hat{\varphi}_{2}$ is defined above, and no investment takes place otherwise.

The proposition states that the opportunistic CRA has no incentive to improve the precision of the signals in the second period. Thus, firms and investors expect $\tilde{s}_{2}=0$, resulting in a completely uninformative signal. It is interesting to note that investment in the project may still occur: If the CRA's reputation for being committed to acquire perfectly informative signals is high enough, investors will nevertheless visit the website and follow the CRA's rating. Notice that this entails the risk that resources are allocated inefficiently since bad projects, rated high erroneously by an opportunistic CRA, may receive financing.

\footnotetext{
${ }^{9}$ Note that we ignore the case of $\varphi_{2}=\varphi_{1}^{H}$ since it lies off the equilibrium path. Note further that the final belief at the end of period 1 is equal to the interim belief $\varphi_{1}^{L}$ when a bad rating is observed. To see this, suppose $r_{1}=L$ and note that $\lambda_{1}^{L} \leq \lambda$. Then Assumption A1 implies that investors choose the outside option, and in turn, that the belief about the CRA's type remains at $\varphi_{1}^{L}$.
} 
We turn now to the analysis of period 1. The opportunistic CRA's maximization problem is then given by

$$
\max _{\left\{s_{1}\right\}}\left[\mathbb{1}_{\varphi_{1} \geq \hat{\varphi}_{1}\left(\tilde{s}_{1}\right)} \pi+\mathbb{1}_{\varphi_{2} \geq \hat{\varphi}_{2}(0)} \pi-c\left(s_{1}\right)\right]
$$

where $\varphi_{2} \in\left\{\varphi_{1}^{H F}, \varphi_{1}, \varphi_{1}^{L}, \varphi_{1}^{H S}\right\}$. It is important to note that the CRA's effort choice in period 1 may influence the investors' prior beliefs in period $2, \varphi_{2}$, measuring the CRA's reputation in that period. As a consequence, the opportunistic CRA may have an incentive to improve the precision of the signal in period 1 . Note also that the main insights of this paper are not driven by the finiteness of the game. The reason is that the payoff in period 2 would be proportional to the net present value of future payoffs to the CRA in an extended version of the model with an infinite horizon. We start our analysis by identifying the opportunistic CRA's optimal effort choice in period 1 for arbitrary investors' beliefs $\tilde{s}_{1}$. For this, note that the marginal expected revenue of a slightly higher informativeness of the signal is zero in two cases: first, when the CRA's initial reputation $\varphi_{1}$ is so high such that $\varphi_{2} \geq \hat{\varphi}_{2}(0)$, independent of the project success in period 1, the CRA obtains positive advertisement revenue $\pi>0$ in period 2 for sure. Second, when the CRA's initial reputation $\varphi_{1}$ is so low that $\varphi_{2}<$ $\hat{\varphi}_{2}(0)$, independent of the project success in period 1 , the advertisement revenue is 0 in period 2. In both cases the CRA gains from reducing the precision of the signal in period 1 whenever $c^{\prime}\left(s_{1}\right)>0$, which is the case for all $s_{1}>0$. Nevertheless, we find that there is a range of reputation levels $\varphi_{1}$, such that the CRA's marginal expected revenue of increasing $s_{1}$ is positive, given arbitrary investors' beliefs. The reason is that ratings produced with higher signal precision reduce the probability that the CRA is revealed to be opportunistic.

The following proposition establishes existence of four different types of perfect Bayesian equilibria. The proof is placed in the Appendix.

Proposition 2 There exist unique values $0<\underline{\varphi} \leq \hat{\varphi}_{2}(0)<\bar{\varphi}<1$ such that the game has four kinds of perfect Bayesian equilibria:

1. Resting on laurels: For $\bar{\varphi} \leq \varphi_{1} \leq 1$, there exists a unique perfect Bayesian equilibrium in which the opportunistic CRA chooses $s_{1}^{*}=0$.

2. Reputation maintenance: For $\hat{\varphi}_{2}(0) \leq \varphi_{1}<\bar{\varphi}$, every perfect Bayesian equilibrium involves the opportunistic CRA choosing $s_{1}^{*}>0$.

3. Reputation building: For $\underline{\underline{ }} \leq \varphi_{1}<\hat{\varphi}_{2}(0)$, there exist perfect Bayesian equilibria in which the opportunistic CRA chooses $s_{1}^{*}>0$.

4. Everything lost: For $0 \leq \varphi_{1}<\hat{\varphi}_{2}(0)$, there exists a perfect Bayesian equilibrium in which the opportunistic CRA chooses $s_{1}^{*}=0$. For $\varphi_{1} \leq \varphi$, this equilibrium is unique.

The proposition states that zero improvement of the signal precision may be an equilibrium outcome. Such equilibria arise whenever the first-period outcome does not affect investors' decision to visit the website in period 2. This happens in two polar cases: First, when the reputation is so high such that investors always expect to benefit from the CRA's ratings $\left(\varphi_{1} \geq \bar{\varphi}\right)$, and second, when the CRA's initial reputation is too low to bring investors to the website, given their pessimistic beliefs 
$\left(\varphi_{1}<\hat{\varphi}_{1}(0)\right)$. Note that $\hat{\varphi}_{1}(0)=\hat{\varphi}_{2}(0)$. We call the first equilibrium type Resting on laurels because the opportunistic CRA can exploit a high reputation and allow itself to be lazy in conducting an elaborate assessment of the projects, and the second type Everything lost because investment will not take place.

However, the proposition also reveals that for a range of intermediate reputation levels increasing the precision of signals is no longer a zero probability event in equilibrium. The key insight of our analysis is that under the advertisement-financed business model improving the precision of signals gives rise to different reputation effects: First, more precise signals reduce the probability that a bad project is erroneously rated good (the bad-project-identification effect). We find that this helps the CRA to maintain a reputation level that is high enough so as to attract investors to its website $\left(\hat{\varphi}_{2}(0) \leq \varphi_{1}<\bar{\varphi}\right)$. To see this note that by (9) the CRA's reputation, irrespective of the CRA's effort, rises when it reports a bad rating or when it reports a high rating that is followed by project success, but falls below $\hat{\varphi}_{2}(0)$, turning investors away in period 2, when it reports a high rating that is followed by project failure. By exerting effort, the CRA reduces the probability that a bad project is erroneously rated good, and hence the probability that a highly-rated project fails. As a result, shirking is not supported in equilibrium for this range of reputation levels. We call this equilibrium type Reputation maintenance because the CRA's effort helps it to maintain its reputation above the critical level $\hat{\varphi}_{2}(0)$.

Second, more precise signals also reduce the probability that a good project is erroneously rated low (the good-project-identification effect). This effect helps the CRA to build a reputation whenever low ratings would deter investors from visiting the website in the future $\left(\varphi \leq \varphi_{1}<\hat{\varphi}_{2}(0)\right)$. The equilibrium of the Reputation building type is in this case sustained by the following considerations. On the one hand, investors would visit the website in period 1 only if they expect the CRA to sufficiently improve its signal precision $\left(\varphi_{1} \geq \hat{\varphi}_{1}\left(\tilde{s}_{1}\right)\right)$. On the other hand, given such investors' beliefs, the CRA would benefit from improving its signal precision by reducing the probability that a highly-rated project fails in period 1 (the badproject-identification effect) - an event that deters investors from visiting the website in period 2, but also by reducing the probability that a bad rating is reported incorrectly (the good-project-identification effect) - an event that matters when bad ratings in period 1 deter investors from visiting the website in period 2. Indeed, for this range of reputation levels, we show that, together with consistent investors' beliefs, the CRA will find it attractive to exert effort in equilibrium. Clearly, investors' beliefs play an important role for the existence of this equilibrium type. As noted above, zero improvement of the signal precision is therefore also always a possible equilibrium outcome in this range of reputation levels below $\hat{\varphi}_{2}(0)$.

\section{Misreporting}

In this section, we assume that the CRA has the choice between truthful reporting and misreporting, that is, announcing a rating different from the obtained signal. Note that under truthful reporting, a good rating still entails the risk of investment failure - an event that reduces the CRA's reputation of obtaining precise signals and 
deters investors from visiting the website in period 2. By contrast, a bad rating will not be followed by investment and thus entails no risk of investment failure. Rating deflation may therefore be a dominant strategy in our basic model when misreporting is possible. Thus, for a better understanding of the CRA's incentives to misreport under the advertisement-financed business model, it seems worth considering a richer setting, ruling out rating deflation as a dominant strategy.

Thus far, we have assumed that investors are homogeneous and that the number of investors remains constant in each period. Yet, the success of highly-rated projects may actually help a CRA to attract additional users to its website. To capture this feature, we modify our setting slightly by allowing the CRA's advertisement revenue to be state-contingent. We assume that the CRA obtains a revenue of $A \pi$, with $A \geq 1$, in period 2 when an $H$-rated project has been successful in period 1 . Note that, for $A=1$, the extended setting reduces to our basic model.

We continue to assume that the committed CRA never misreports and focus on the opportunistic CRA's incentives to improve the precision of signals and report the signals truthfully. Consider equilibria of the Reputation maintenance type identified in Proposition 2. In these equilibria, investors turn away from the website in period 2 only when an $H$-rated project has failed in period 1 . Therefore, the CRA will have an incentive to report the signals truthfully if and only if

$\alpha \lambda\left(\frac{1}{2}+s_{1}^{*}\right) A \pi+\left[(1-\lambda)\left(\frac{1}{2}+s_{1}^{*}\right)+\lambda\left(\frac{1}{2}-s_{1}^{*}\right)\right] \pi-c\left(s_{1}^{*}\right) \geq \max \{\alpha \lambda A \pi, \pi\}$

where $s_{1}^{*}>0$ maximizes the LHS of (14). The first two terms on the LHS are the CRA's expected second-period payoff from exerting effort $s_{1}^{*}$ and reporting the signal truthfully. The RHS of (14) represents the CRA's expected second-period payoff from not improving the precision of the signals and misreporting, that is, reporting an $\mathrm{H}$ rating when a bad signal is observed, $\alpha \lambda A \pi$, or an $L$-rating when a good signal is observed, $\pi$.

Next, consider the equilibrium of the Reputation building type identified in Proposition 2. We know from the proof of the proposition that there are two cases to distinguish, depending on the investors' response to the ratings and project outcome: First, there may exist equilibria in which investors turn away from the website in period 2 only when an $H$-rated project has failed in period 1 . For these equilibria, the incentive compatibility constraint for truthful reporting is given by (14). Second, there may exist equilibria in which investors choose to visit the website in period 2 only when an $H$-rated project has been successful. For these equilibria, the incentive compatibility constraint is given by

$$
\alpha \lambda\left(\frac{1}{2}+s_{1}^{*}\right) A \pi-c\left(s_{1}^{*}\right) \geq \max \{\alpha \lambda A \pi, 0\}
$$

where $s_{1}^{*}>0$ maximizes the LHS of (15).

Not surprisingly, we find that reporting signals truthfully is not always incentive compatible. Indeed, since $c\left(s_{1}\right)>0$ for $s_{1}>0$, it is easy to see that constraint (15) cannot be fulfilled. Thus, in the Reputation building equilibria in which investors turn away whenever the CRA announces an $L$-rating, the CRA always has an incentive 
to inflate ratings. Furthermore, constraint (14) implies that the cost of improving the signal precision $c\left(s_{1}^{*}\right)$ has to be sufficiently small. Assuming that this cost is close to zero at $s_{1}=1 / 2$, we provide sufficient conditions for the existence of equilibria involving positive efforts and truth-telling under the advertisement-financed business model.

Proposition 3 Suppose that revenues are state contingent with $\alpha A \geq 1$, and that the cost of improving the signal precision $c(1 / 2)$ is close to zero. Then reporting signals truthfully is incentive compatible in every equilibrium of the Reputation maintenance type and in every equilibrium of the Reputation building type in which investors turn away from the website in period 2 only when an $H$-rated project has failed in period 1 .

Thus, truthful reporting can be induced if the increase in advertisement revenue associated with is the success of a highly-rated project, $\alpha A$, is larger than revenue under the "safe option" of announcing an $L$-rating even though a good signal is received. As the probability of success of good projects, $\alpha$, or the increase in advertisement revenue due to successful projects, $A$, get smaller, the CRA eventually has an incentive to deflate ratings, as in our basic model.

For a static environment in which the CRA's costly effort determines the signal precision, Kashyap and Kovrijnykh (2016) derive an optimal compensation structure to provide incentives to the CRA to exert effort and report the signals truthfully. Their Proposition 1 states that the CRA should be rewarded in only two cases: if it announces the high rating and the project succeeds or if it announces the low rating. The CRA should never be paid for announcing the high rating if it is followed by the project's failure. While the optimal structure is not implementable under the issuer-pays or the investor-pays model, Kashyap and Kovrijnykh (2016) find that the investor-pays model generates a higher rating accuracy than the issuer-pays model. The reason is that issuers would not be willing to pay for low ratings. It is interesting to note that the optimal compensation structure identified in Kashyap and Kovrijnykh (2016) can be provided by an advertisement-financed business model with state-contingent revenues as considered in our paper. The crucial element of the advertisement-financed model is that investors are deterred when a highly-rated project fails, resulting in zero revenue for the CRA.

\section{Conclusions}

Previous research has shown that traditional CRA business models - the investorpays and the issuer-pays model - provide incentives to produce less informative signals than are socially optimal and to distort ratings in favor of issuers or investors, respectively (cf. Kashyap and Kovrijnykh (2016)).

In this paper, we consider an alternative business model for CRAs which is free of charge for issuers and investors. The CRA earns revenue from advertisements displayed on the online platform where the ratings are published. Investors are attracted to this platform when they regard ratings as valuable information which turns out 
to be the case when the CRA has a sufficiently high reputation of being committed to provide effort and report truthfully. We investigate whether this advertisementbased business model provides sufficient reputational incentives to generate precise information and to report this information truthfully in the form of ratings. Our main findings are: First, for a range of intermediate reputation levels, the advertisementfinanced business model implies that a CRA can maintain or build a reputation for accuracy by improving the precision of its signals. The reason is that more precise signals reduce both, the probability that a bad project is erroneously rated good (the bad-project-identification effect) and the probability that a good project is erroneously rated low (the good-project-identification effect). These effects induce the CRA to exert effort in equilibrium. Second, truthful reporting can be induced if advertisement revenues are state-contingent and sufficiently high.

Future research will investigate the role of competition under the advertisementbased business model. Compared to the issuer-pays model, competition might be more desirable because advertisement financing does not involve the problem of ratings shopping, which is exacerbated by competition under the issuer-pays model (cf. Skreta and Veldkamp (2009) and Bolton et al. (2012)). However, competition may reduce efficiency for other reasons than ratings shopping, for example, by growing pressure on the CRAs to further reduce their costs, and in turn, reduce the informativeness of the signals about the project's quality. Thus, whether competition between advertisement-financed CRAs is socially optimal remains an open question.

\section{Appendix A: Proofs}

Proof of Proposition 1 Since $c^{\prime}\left(s_{2}\right)>0$ for all $s_{2}>0$, the maximum of (12) is attained at $s_{2}=0$. It is easy to see that this is the unique optimal action for the opportunistic CRA in $t=2$. Recall that $\hat{\varphi}_{2}\left(\tilde{s}_{2}\right)$ denotes the lowest CRA reputation at the beginning of period 2 such that (10) still holds. The threshold is obtained by solving $\alpha \lambda_{2}^{H} R_{2}=1$ for $\varphi_{2}$, where $\lambda_{2}^{H}$ is defined by (5), and then substituting $R_{2}$ by $X$. Inserting $\tilde{s}_{2}=0$, yields

$$
\hat{\varphi}_{2}(0)=\frac{1-\alpha \lambda X}{1+\alpha \lambda X-2 \lambda}
$$

with $0<\hat{\varphi}_{2}(0)<1$ by Assumption A1. Thus, if $\varphi_{2} \geq \hat{\varphi}_{2}(0)$, investors will visit the website and invest upon observing a good rating.

Proof of Proposition 2 We make use of the following definitions:

$$
\hat{\varphi}_{1}^{\omega}\left(\tilde{s}_{1}\right) \equiv \min \left\{\varphi_{1}: \varphi_{1}^{\omega}\left(\varphi_{1}, \tilde{s}_{1}\right) \geq \hat{\varphi}_{2}(0)\right\} \text { for } \omega \in\{H F, L, H S\}
$$

That is, given investors' belief in period 1 of $\tilde{s}_{1}$ and a first-period history of $\omega \in\{H F, L, H S\}, \hat{\varphi}_{1}^{\omega}\left(\tilde{s}_{1}\right)$ denotes the threshold that $\varphi_{1}$ has to exceed so that advertisement revenue will be generated in period 2 . It is easy to verify that

$$
\hat{\varphi}_{1}^{H S}\left(\tilde{s}_{1}\right) \leq \hat{\varphi}_{1}^{L}\left(\tilde{s}_{1}\right) \leq \hat{\varphi}_{1}(0) \leq \hat{\varphi}_{1}^{H F}\left(\tilde{s}_{1}\right)
$$


for all $\tilde{s}_{1} \geq 0$. Furthermore,

$$
\begin{aligned}
& \bar{\varphi} \equiv \hat{\varphi}_{1}^{H F}(0) \\
& \underline{\varphi} \equiv \min \left\{\varphi_{1}: \hat{\varphi}_{1}^{H S}\left(\tilde{s}_{1}\right)=\hat{\varphi}_{1}\left(\tilde{s}_{1}\right)\right\} \text { for } \tilde{s}_{1} \geq 0,
\end{aligned}
$$

where $\hat{\varphi}_{1}^{H S}\left(\tilde{s}_{1}\right)$ and $\hat{\varphi}_{1}\left(\tilde{s}_{1}\right)$ are defined by (16) and (11), respectively. Note that $\hat{\varphi}_{1}(0)=\hat{\varphi}_{2}(0)$.

We are now able prove the existence of the four equilibrium types. See Fig. 2 for an illustration of the different regions in the $\tilde{s}_{1} \times \varphi_{1}$ space.

(i) Resting on laurels: Suppose that $\tilde{s}_{1}=0$ and $\varphi_{1} \geq \bar{\varphi}$. The CRA's payoff function is then $2 \pi-c\left(s_{1}\right)$, which is maximized at $s_{1}^{*}=0$. This is consistent with $\tilde{s}_{1}=0$ and, therefore, constitutes a perfect Bayesian equilibrium. To prove

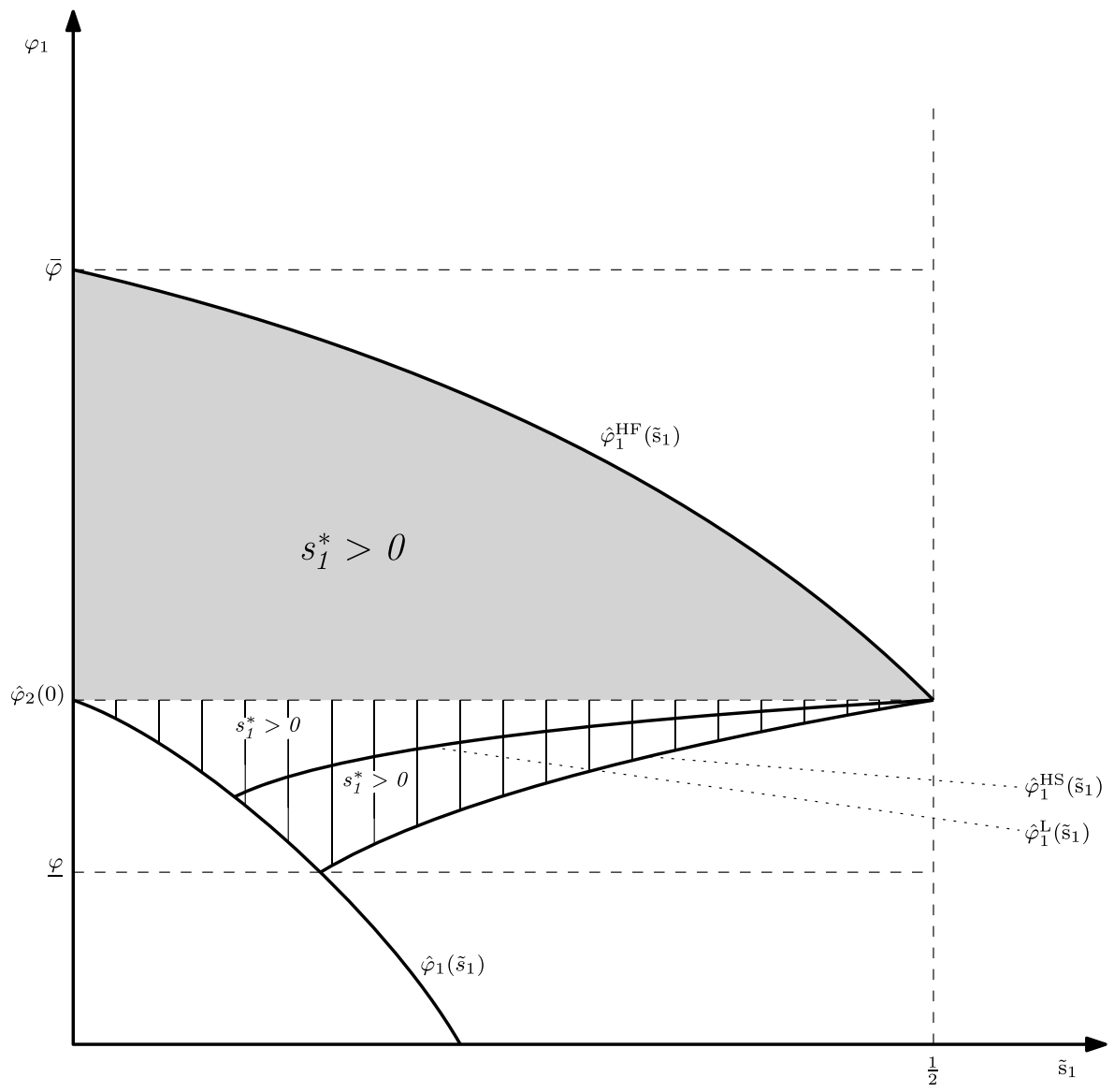

Fig. 2 Regions in the $\tilde{s}_{1} \times \varphi_{1}$ space 
uniqueness, assume towards a contradiction that there exists another equilibrium with $s_{1}=\tilde{s}_{1}>0$. It is easily verified that $\hat{\varphi}_{1}^{H F}\left(\tilde{s}_{1}\right)<\bar{\varphi} \leq \varphi_{1}$ for $\tilde{s}_{1}>0$. Since the CRA's payoff function is still $2 \pi-c\left(s_{1}\right)$, the CRA has a strictly profitable deviation, namely, $s_{1}=0$.

(ii) Everything lost: Suppose that $\varphi_{1}<\hat{\varphi}_{2}(0)$ and $\tilde{s}_{1}=0$. Since $\hat{\varphi}_{1}(0)=\hat{\varphi}_{2}(0)$, investors will not pay attention to first-period credit ratings. Accordingly, the CRA does not generate revenue in the first period and there is no belief update. This implies that the second-period revenue is also zero. Thus, the CRA's payoff function is given by $-c\left(s_{1}\right)$, which is maximized by $s_{1}^{*}=0$. This is consistent with $\tilde{s}_{1}=0$ and, therefore, constitutes a perfect Bayesian equilibrium. We now prove uniqueness. Suppose that $\varphi_{1}<\varphi$. Then the opportunistic CRA's payoff is $-c\left(s_{1}\right)$ if $\left(\tilde{s}_{1}, \varphi_{1}\right)$ fulfills $\varphi_{1}<\hat{\varphi}_{1}\left(\overline{s_{1}}\right)$, and $\pi-c\left(s_{1}\right)$ otherwise. In both cases, $s_{1}^{*}=0$ is the unique optimal technology choice.

(iii) Reputation maintenance: Suppose that $\hat{\varphi}_{1}(0)<\varphi_{1}<\bar{\varphi}$. This implies that $\varphi_{1}>\hat{\varphi}_{1}^{L}\left(\tilde{s}_{1}\right)$, as defined by (16). That is, $\varphi_{1}$ is high enough to generate a positive advertisement revenue in period 2 after the report of an $L$-rating in period 1. For $\tilde{s}_{1}>0$, there two cases to consider: First, suppose that $\hat{\varphi}_{1}(0)<$ $\varphi_{1}<\hat{\varphi}_{1}^{H F}\left(\tilde{s}_{1}\right)$. In this case, the CRA's second-period revenue is zero only when a highly-rated project fails at the end of period 1. The CRA's payoff is then given by $\left[2-(1-\alpha) \lambda\left(\frac{1}{2}+s_{1}\right)-(1-\lambda)\left(\frac{1}{2}-s_{1}\right)\right] \pi-c\left(s_{1}\right)$. It is easily verified that this payoff is maximized at $s_{1}^{*}>0$. Second, suppose that $\hat{\varphi}_{1}^{H F}\left(\tilde{s}_{1}\right) \leq \varphi_{1}<\bar{\varphi}$. The CRA's payoff in this case is $2 \pi-c\left(s_{1}\right)$, which is maximized by $s_{1}=0$. However, for $\tilde{s}_{1}=0$, we have that $\varphi_{1}<\hat{\varphi}_{1}^{H F}\left(\tilde{s}_{1}\right)=\bar{\varphi}$, a contradiction. Hence, there cannot exist an equilibrium with $s_{1}^{*}=0$ in this case.

(iv) Reputation building: Suppose that $\underline{\varphi} \leq \varphi_{1} \leq \hat{\varphi}_{2}(0)$ and $\tilde{s}_{1}>0$.

For $\varphi_{1}<\hat{\varphi}_{1}\left(\tilde{s}_{1}\right)$, investors will not pay attention to first-period credit ratings. Accordingly, the CRA does not generate revenue in the first period and there is no belief update. This implies that the second-period revenue is also zero. Thus, the CRA's payoff function is given by $-c\left(s_{1}\right)$, which is maximized by $s_{1}^{*}=0$. This is not consistent with $\tilde{s}_{1}>0$ and, hence, does not constitute a perfect Bayesian equilibrium.

For $\varphi_{1} \geq \hat{\varphi}_{1}\left(\tilde{s}_{1}\right)$, we distinguish three subcases: First, we consider pairs of $\left(\varphi_{1}, \tilde{s}_{1}\right)$ such that $\varphi_{1} \geq \hat{\varphi}_{1}^{L}\left(\tilde{s}_{1}\right)$. The CRA's second-period revenue is then zero only when a highly-rated project fails at the end of period 1. The CRA's payoff is then given by $\left[2-(1-\alpha) \lambda\left(\frac{1}{2}+s_{1}\right)-(1-\lambda)\left(\frac{1}{2}-s_{1}\right)\right] \pi-c\left(s_{1}\right)$, which is maximized at $s_{1}^{*}>0$. Together with consistent beliefs $\tilde{s}_{1}=s_{1}^{*}$, this constitutes a perfect Bayesian equilibrium of the Reputation building type. Second, we consider pairs of $\left(\varphi_{1}, \tilde{s}_{1}\right)$ such that $\hat{\varphi}_{1}^{H S}\left(\tilde{s}_{1}\right) \leq \varphi_{1}<\hat{\varphi}_{1}^{L}\left(\tilde{s}_{1}\right)$. The CRA's second-period revenue is then positive only when a highly-rated project succeeds at the end of period 1. The CRA's payoff is then given by $\pi+\alpha \lambda\left(\frac{1}{2}+s_{1}\right) \pi-c\left(s_{1}\right)$. It is easily verified that this payoff is maximized at $s_{1}^{*}>0$. Together with consistent beliefs $\tilde{s}_{1}=s_{1}^{*}$, this constitutes a perfect Bayesian equilibrium of the Reputation building type. Third, consider pairs 
of $\left(\varphi_{1}, \tilde{s}_{1}\right)$ such that $\varphi_{1}<\hat{\varphi}_{1}^{H S}\left(\tilde{s}_{1}\right)$. The CRA's second-period revenue is then zero for all ratings. The CRA's payoff is then given by $\pi-c\left(s_{1}\right)$, which is maximized by $s_{1}^{*}=0$. This is not consistent with $\tilde{s}_{1}>0$ and, hence, does not constitute a perfect Bayesian equilibrium.

Proof of Proposition 3 By Proposition 2, equilibria of the Reputation maintenance type exist for $\hat{\varphi}_{2}(0) \leq \varphi_{1}<\bar{\varphi}$. These thresholds stay the same under the statecontingent revenue structure. Checking constraint (14) for $s_{1}^{*}=\frac{1}{2}$ reveals that it is satisfied if $A \geq \frac{1}{\alpha}$. By continuity, there exists a $\hat{s}_{1}$ such that the constraint is also satisfied for a range of effort levels $\hat{s}_{1}<s_{1}^{*}<\frac{1}{2}$. By Proposition 2, equilibria of the Reputation building type exist for $\underline{\varphi} \leq \varphi_{1}<\hat{\varphi}_{2}(0)$. These thresholds stay the same under the state-contingent revenue structure. From the proof of Proposition 2, we know that for pairs of $\left(\varphi_{1}, \tilde{s}_{1}\right)$ such that $\varphi_{1} \geq \hat{\varphi}_{1}^{L}\left(\tilde{s}_{1}\right)$, the CRA's second-period revenue is then zero only when a highly-rated project fails at the end of period 1. The incentive compatibility constraint for truth-telling is then also given by (14). For pairs of $\left(\varphi_{1}, \tilde{s}_{1}\right)$ such that $\hat{\varphi}_{1}^{H S}\left(\tilde{s}_{1}\right) \leq \varphi_{1}<\hat{\varphi}_{1}^{L}\left(\tilde{s}_{1}\right)$, the CRA's second-period revenue is then positive only when a highly-rated project succeeds at the end of period 1 . The incentive compatibility constraint for truth-telling is then given by (15), which cannot be satisfied.

Acknowledgements The work in this paper was conducted in part while one of the authors was visiting the Toulouse School of Economics, whose hospitality and support is gratefully acknowledged. We also wish to thank an anonymous referee, Bernhard Bartels, Andreas Barth, Alessa Durst, Daniel Garrett, Georgios Katsenos, Thomas Mariotti, Günther Strobl, Lawrence J. White, Takuro Yamashita and seminar participants at the Toulouse School of Economics and the Annual Conference of the Verein für Socialpolitik for helpful remarks.

Author Contributions Both authors contributed, read and approved the final manuscript.

Funding Open Access funding enabled and organized by Projekt DEAL. The authors received no specific funding for this work.

\section{Declarations}

Conflicts of Interest / Competing interests The authors declare that there are no conflicts of interest or competing interests.

Open Access This article is licensed under a Creative Commons Attribution 4.0 International License, which permits use, sharing, adaptation, distribution and reproduction in any medium or format, as long as you give appropriate credit to the original author(s) and the source, provide a link to the Creative Commons licence, and indicate if changes were made. The images or other third party material in this article are included in the article's Creative Commons licence, unless indicated otherwise in a credit line to the material. If material is not included in the article's Creative Commons licence and your intended use is not permitted by statutory regulation or exceeds the permitted use, you will need to obtain permission directly from the copyright holder. To view a copy of this licence, visit http://creativecommons.org/licenses/by/4.0/. 


\section{References}

Ahmed T, Kwon C (2012) Pricing game of online display advertisement publishers. Eur J Oper Res 219(2):477-487. https://doi.org/10.1016/j.ejor.2012.01.008

Anderson SP (2012) Advertising on the internet. In: Peitz M, Waldfogel J (eds) The Oxford handbook of the digital economy. Oxford University Press, Oxford, pp 355-396

Anderson SP, Jullien B (2015) The advertising-financed business model in two-sided media markets. In: Simon P, Anderson SP, Waldfogel J, Strömberg D (eds) Handbook of media economics. 1st edn. North-Holland, Amsterdam, pp 41-90. https://doi.org/10.1016/B978-0-444-62721-6.00002-0

Berenson A (2001) Enron's collapse: the rating agencies; debt rankings finally fizzle, but the deal fizzled first. The New York Times. https://www.nytimes.com/2001/11/29/business/ enron-s-collapse-rating-agencies-debt-rankings-finally-fizzle-but-deal-fizzled.html. Accessed 18 Feb 2021

Bolton P, Freixas X, Shapiro J (2012) The credit ratings game. J Financ 67(1):85-112. https://doi.org/10.1111/j.1540-6261.2011.01708.x

Bouvard M, Levy R (2018) Two-sided Reputation in certification markets. Manage Sci 64(10):4755-4774. https://doi.org/10.1287/mnsc.2017.2742

Chakraborty I, Saretto A, Wardlaw (2019) Can a platform-pays mechanism reduce credit rating bias? SSRN Working Paper. https://doi.org/10.2139/ssrn.2489471

Chu CS, Kim J (2018) The current state of knowledge on electronic word-of-mouth in advertising research. Int J Advert 37(1):1-13. https://doi.org/10.1080/02650487.2017.1407061

Chu CS, Rysman M (2019) Competition and strategic incentives in the market for credit ratings: empirics of the financial crisis of 2007. Am Econ Rev 109(10):3514-55. https://doi.org/10.1257/aer.20140773

Evans DS (2008) The economics of the online advertising industry. Rev Netw Econ 7(3):1-33. https:// ssrn.com/abstract $=1086473$

Frenkel S (2015) Repeated interaction and rating inflation: a model of double reputation. Am Econ JMicroecon 7(1):250-280. https://doi.org/10.1257/mic.20110077

Fulghieri P, Strobl G, Xia H (2014) The economics of solicited and unsolicited credit ratings. Rev Financ Stud 27(2):484-518. https://doi.org/10.1093/rfs/hht072

Huete-Alcocer N (2017) A literature review of word of mouth and electronic word of mouth: implications for consumer behavior. Front Psychol 8:1256. https://doi.org/10.3389/fpsyg.2017.01256

Jaffee DM (2009) Comment on "Rating the raters" by Jérôme Mathis, James McAndrews, and JeanCharles Rochet". J Monetary Econ 56(2):675-677. https://doi.org/10.1016/j.jmoneco.2009.05.003

Kashyap AK, Kovrijnykh N (2016) Who should pay for credit ratings and how? Rev Financ Stud 29(2):420-465. https://doi.org/10.1093/rfs/hhv127

Kreps DM, Wilson R (1982) Reputation and imperfect information. J Econ Theory 27(2):253-279. https://doi.org/10.1016/0022-0531(82)90030-8

Lippert S, Spagnolo G (2011) Networks of relations and word-of-mouth communication. Game Econ Behav 72(1):202-217. https://doi.org/10.1016/j.geb.2010.08.010

Lu X, Ba S, Huang L, Feng Y (2013) Promotional marketing or word-of-mouth? Evidence from online restaurant reviews. Inf Syst Res 24(3):596-612. https://doi.org/10.1287/isre.1120.0454

Luca M (2016) Designing online marketplaces: trust and reputation mechanisms. Harvard Business School Working Paper 17-017. https://doi.org/10.1086/688845

Mathis J, McAndrews J, Rochet JC (2009) Rating the raters: Are reputation concerns powerful enough to discipline rating agencies? J Monetary Econ 56(2):657-674. https://doi.org/10.1016/j.jmoneco.2009.04.004

Milgrom P, Roberts J (1982) Predation, reputation, and entry deterrence. J Econ Theory 27(2):280-312. https://doi.org/10.1016/0022-0531(82)90031-X

Pacces AM, Romano A (2015) A strict liability regime for credit rating agencies. Am Bus Law J 52(4):673-720. https://doi.org/10.2139/ssrn.2405509

Sangiori F, Spatt CS (2017) The economics of credit rating agencies. Found Trends Finance 12:1-116. https://doi.org/10.2139/ssrn.3055889

Skreta V, Veldkamp L (2009) Ratings shopping and asset complexity: A theory of ratings inflation. J Monetary Econ 56(5):678-695. https://doi.org/10.1016/j.jmoneco.2009.04.006

Spulber D (2019) The economics of markets and platforms. J Econ Manage Strat 28(1):159-172. https://doi.org/10.1111/jems.12290 
Strausz R (2005) Honest certification and the threat of capture. Int J Ind Organ 23(1):45-62. https://doi. org/10.1016/j.ijindorg.2004.09.002

White LJ (2010) Markets: "The Credit Rating Agencies”. J Econ Perspect 24(2):211-226. https://doi.org/10.1257/jep.24.2.211

White LJ (2013) Credit rating agencies: an overview. Annu Rev Financ 5(1):93-122. https://doi.org/10. 1146/annurev-financial-110112-120942

White LJ (2016) Credit Rating Agencies: an analysis through the lenses of industrial organization, finance and regulation. Pac Econ Rev 21(2):202-226. https://doi.org/10.1111/1468-0106.12164

Publisher's note Springer Nature remains neutral with regard to jurisdictional claims in published maps and institutional affiliations. 